\title{
POLYTHELIA IN CARDIO-ARTERIAL DISEASE
}

\author{
BY \\ WILLIAM EVANS \\ From the Cardiac Department of the London Hospital \\ Received April 4, 1958
}

Polythelia ( $\pi \circ \lambda v^{\prime}=$ many; $\theta \eta \lambda \eta^{\prime}=$ nipple) or the presence of accessory nipples has long been held to be an atavistic manifestation (Lichtenstern, 1878; Darwin, 1888). The coincidence of polythelia, therefore, increases the probability that a disease arises from a congenital predisposition to it.

It is the purpose of this paper to examine such a view in so far as it may apply to heart disease, and especially to the arterial changes associated with hypertension, both systemic and pulmonary.

\section{SCOPE OF THE INQUIRY}

Polythelia was sought in 2000 consecutive cases examined on account of symptoms that suggested some cardiovascular disorder. Following clinical, electrocardiographic and cardioscopic examination, 1059 subjects were found to be free from disease. In the remaining 941 patients some affection of the cardio-arterial system was present in most of them.

The search for accessory nipples was made exclusively along the embryonic milk line which extends from the axilla to the groin (Fig. 1). This primary line is seen in the human embryo at the sixth week as a ridge of ectoderm joining the bases of the upper and lower limb buds on each side of the trunk. As pointed out by Bruce (1879), elements of the supernumerary nipple include papilla, areola, follicle, and hair, and in a given case these are variously represented (Fig. 2, 3, and 4). Provided the suspected vestige lies along the embryonic milk line, its identification is never in doubt, and it needs emphasis that often it appears as a mere depressed dimple (Fig. 4). During the assembling of the present series, no example of accessory nipple was met with that was away from the milk line, nor did any instance of polymastia occur. Such skin lesions as congenital moles or stains, plane warts, or papillomata were easily identified even when situated in the course of the milk line as sometimes happened.

It was unusual to find accessory nipples occupying a site above the level of the natural nipples, and most commonly they presented a short distance below, and always above the level of the umbilicus in this series.

\section{INCIDENCE IN HEALTHY SUBJECTS}

Guest (1923) found extra nipples in 83 among some 20,000 school children, an incidence of only 0.4 per cent. In seven the accessory nipple was on both sides, otherwise it was single; it was commoner in the girls for 53 were girls and 30 were boys. de Cholnoky (1939) found polythelia in 1 to 2 per cent of the population, and Hamblen (1945) gave a rough estimate of 1 per cent. Experience does not confirm a statement made by Keith (1948) that one or more supernumerary nipples found between the axilla and groin, indicating a wide distribution for these ancestral glands, was a common occurrence.

In my series polythelia was present in 49 among 1059 healthy subjects, an incidence of nearly 5 per cent. Only one accessory nipple was found in the majority, but it was not rare to find two, and exceptionally three. The incidence disclosed no significant sex preponderance. 


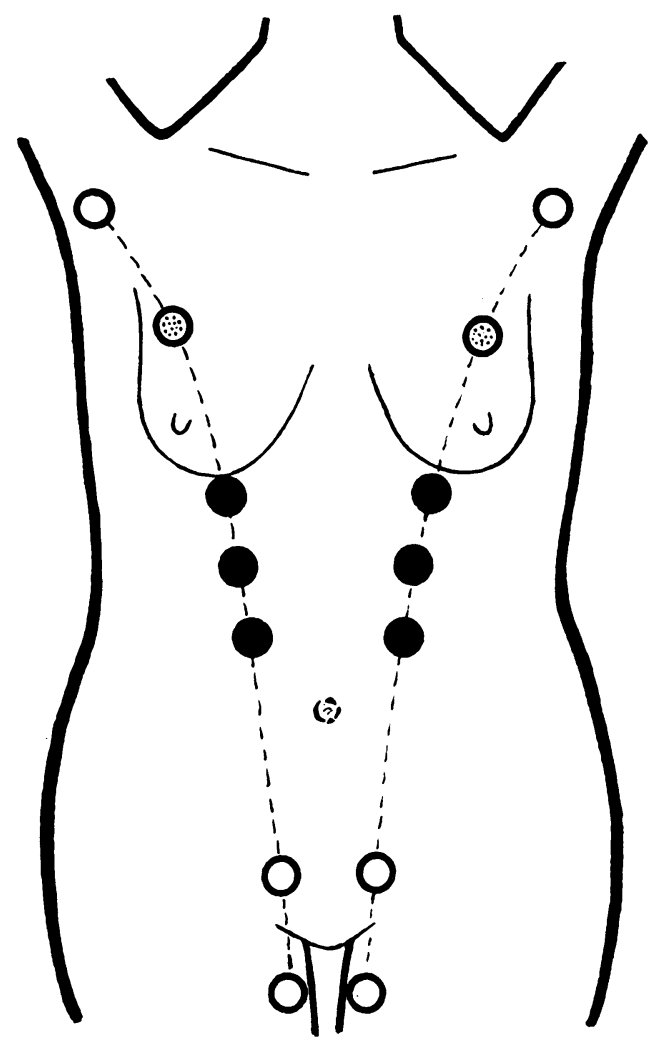

FIG. 1.-Schematic representation of the distribution of supernumerary nipples along the embryonic milk line.
Rare
(ㄱ) Unusual
- Usual

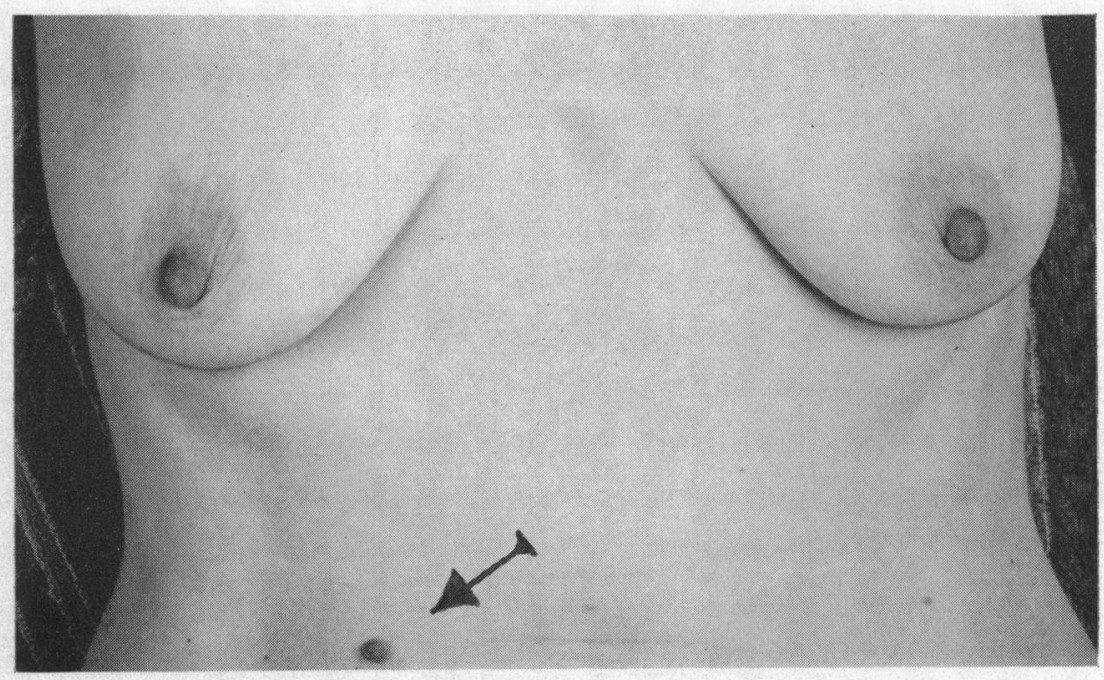

Fig. 2.-A single accessory nipple in a patient with mitral stenosis uncomplicated by pulmonary hypertension. 

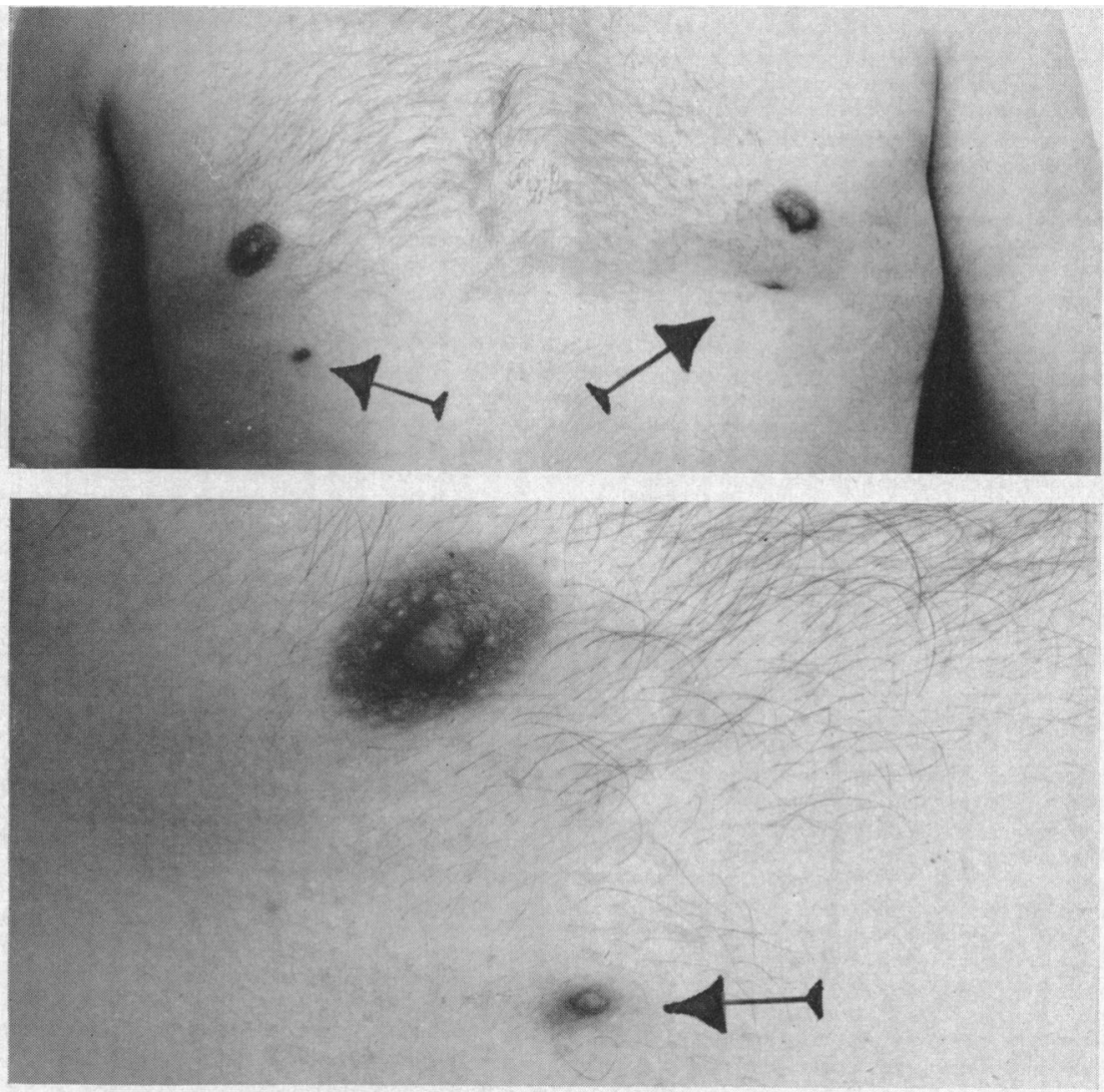

Fig. 3-Two accessory nipples (one magnified in lower picture) from a patient with systemic hypertension.
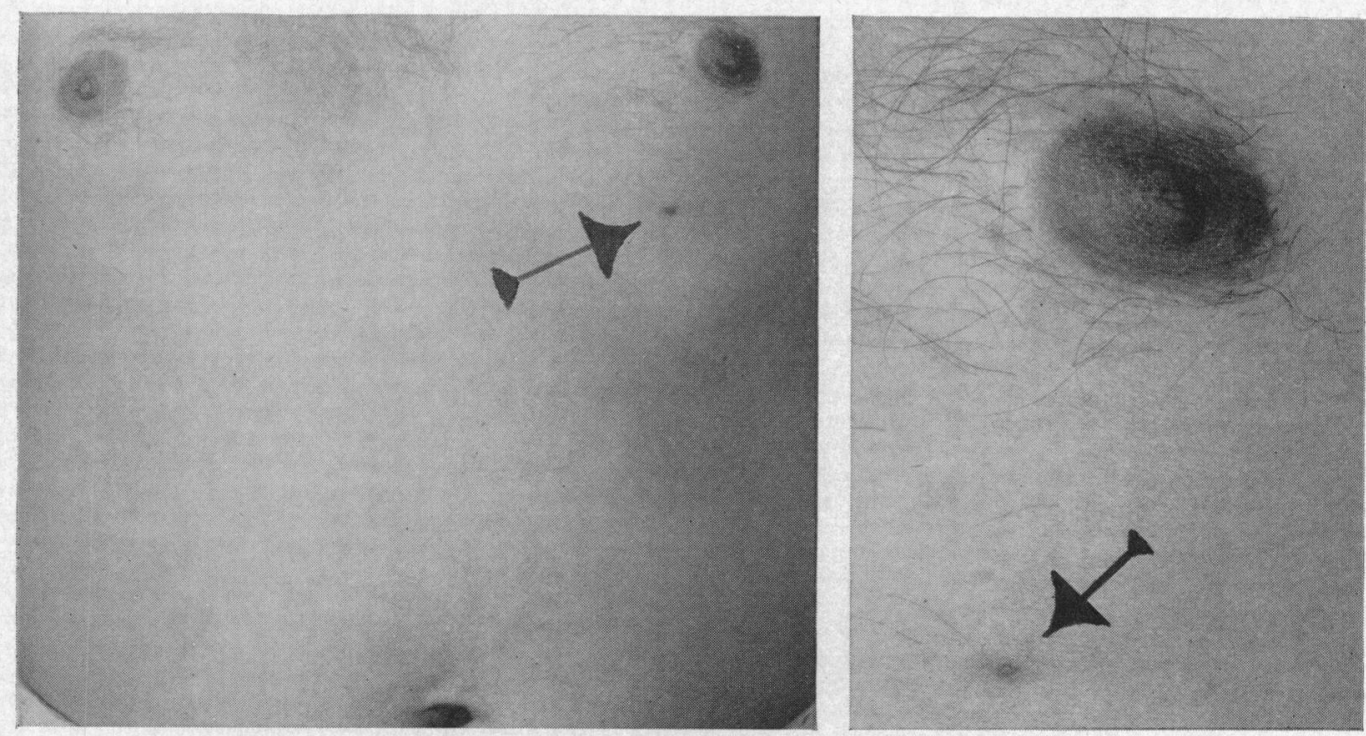

FIG. 4.-The common diminutive type of accessory nipple (magnified in picture on the right) from a patient with mitral stenosis and pulmonary hypertension. 


\section{Polythelia in Patients with Cardio-Arterial Disease}

Among the 2000 cases examined consecutively there were many with physical signs that pointed to some abnormality of the cardio-arterial system. The significance of polythelia in these was examined after allocating the patients into separate clinical groups, namely those with acquired or congenital heart disease, and those showing a raised blood pressure either in the systemic or pulmonary circulation.

Miscellaneous Heart Disease. Among 365 patients with cardiac infarction where cardiac pain was associated with characteristic electrocardiographic changes, there were 32 with polythelia. This incidence of 9 per cent is not significantly higher than in healthy subjects (Table I).

TABLE I

Incidence of Polythelia in Healthy Subjects and in Patients with Heart Disease

\begin{tabular}{|c|c|c|c|c|c|c|c|}
\hline \multirow{2}{*}{\multicolumn{3}{|c|}{ Clinical state }} & \multirow{2}{*}{ Healthy } & \multirow{2}{*}{$\begin{array}{c}\text { Congenital } \\
\text { heart disease }\end{array}$} & \multirow{2}{*}{$\begin{array}{l}\text { Cardiac } \\
\text { infarction }\end{array}$} & \multicolumn{2}{|c|}{$\begin{array}{l}\text { Valvular } \\
\text { heart disease }\end{array}$} \\
\hline & & & & & & Aortic & Mitral \\
\hline $\begin{array}{l}\text { Total .. } \\
\text { Polythelia . . } \\
\text { Near percentage }\end{array}$ & $\begin{array}{l}\cdots \\
\cdots \\
\cdots\end{array}$ & $\begin{array}{l}\ldots \\
\cdots \\
\ldots\end{array}$ & $\begin{array}{r}1059 \\
49 \\
5\end{array}$ & $\begin{array}{r}107 \\
15 \\
14\end{array}$ & $\begin{array}{r}365 \\
32 \\
9\end{array}$ & $\begin{array}{r}81 \\
8 \\
9\end{array}$ & $\begin{array}{r}186 \\
26 \\
14\end{array}$ \\
\hline
\end{tabular}

Out of 81 patients with aortic valve disease there were 8 instances of polythelia, an incidence of 9 per cent, which was no different in the cases of aortic stenosis, where the lesion in some might have been congenital by nature, and in the cases of acquired aortic incompetence. A higher incidence of 14 per cent in mitral valve disease is a reflection of the common association with pulmonary hypertension, and this is discussed later in the text.

In 32 patients there was evidence of myocardial disease other than cardiac infarction from coronary arterial disease, and none of them presented with cardiac pain. Polythelia was found in $14(44 \%)$ of these. Nine of the cases showed bundle-branch block, four had complete heart block, and two were instances of familial cardiomegaly. In the remaining 17 patients the lesion was considered to be in the nature of a tardy myocardial fibrosis or myocarditis. The incidence of polythelia in these separate clinical states is given in Table II.

TABLE II

Incidence of Polythelia in Patients with Cardiomyopathy other than from Coronary Arterial Disease

\begin{tabular}{|c|c|c|c|c|c|c|c|}
\hline \multirow{2}{*}{ Clinical state } & & \multirow{2}{*}{ Healthy } & \multicolumn{5}{|c|}{ Cardiomyopathy } \\
\hline & & & Myocarditis & $\begin{array}{c}\text { Familial } \\
\text { cardiomegaly }\end{array}$ & $\begin{array}{c}\text { Bundle-branch } \\
\text { block }\end{array}$ & $\begin{array}{l}\text { Complete } \\
\text { heart block }\end{array}$ & Total \\
\hline $\begin{array}{l}\text { Total . } \\
\text { Polythelia } \\
\text { Near percentage }\end{array}$ & $\begin{array}{l}\cdots \\
\cdots \\
\cdots\end{array}$ & $\begin{array}{r}1059 \\
49 \\
5\end{array}$ & $\begin{array}{r}17 \\
7 \\
-\end{array}$ & $\begin{array}{r}2 \\
2 \\
-\end{array}$ & $\begin{array}{r}9 \\
4 \\
-\end{array}$ & $\begin{array}{r}4 \\
1 \\
-\end{array}$ & $\begin{array}{l}32 \\
14 \\
44\end{array}$ \\
\hline
\end{tabular}

Congenital Heart Disease. Polythelia was present in 3 out of 26 cases of pulmonary stenosis, of which 19 were of the lone kind and 7 were examples of Fallot syndrome.

It occurred only once among 11 with aortic coarctation, and was absent in two patients with Ebstein syndrome, one with congenital dextrocardia, and one with cardio-aortic fistula. It was present in a single example of Marfan's disease.

The incidence of polythelia in auricular septal defect, ventricular septal defect and patent ductus arteriosus is discussed later under pulmonary hypertension. 
Raised Systemic Blood Pressure. There were 108 cases where the blood pressure was raised to readings of $200 / 110 \mathrm{~mm}$. of $\mathrm{Hg}$, and these were separated into two groups depending on the presence or absence of cardio-arterial derangement (Table III).

TABLE III

Incidence of Polythelia in Patients with Systemic Hypertension and Pulmonary Hypertension, COMPaRed With that in Healthy SubJects

\begin{tabular}{|c|c|c|c|c|c|c|}
\hline \multirow[t]{2}{*}{ Clinical state } & & \multirow[t]{2}{*}{ Healthy } & \multicolumn{2}{|c|}{$\begin{array}{c}\text { Raised } \\
\text { systemic blood pressure }\end{array}$} & \multicolumn{2}{|c|}{$\begin{array}{c}\text { Raised } \\
\text { pulmonary blood pressure }\end{array}$} \\
\hline & & & Hypertension & Hypertonia & Hypertension & Hypertonia \\
\hline $\begin{array}{l}\text { Total .. } \\
\text { Polythelia } \\
\text { Near percentage }\end{array}$ & $\begin{array}{l}\cdots \\
\cdots \\
\ldots\end{array}$ & $\begin{array}{r}1059 \\
49 \\
5\end{array}$ & $\begin{array}{l}66 \\
23 \\
35\end{array}$ & $\begin{array}{r}42 \\
2 \\
5\end{array}$ & $\begin{array}{l}73 \\
32 \\
44\end{array}$ & $\begin{array}{r}229 \\
15 \\
7\end{array}$ \\
\hline
\end{tabular}

In the first group of 66 patients, the raised blood pressure was associated with contracted peripheral arteries and retinal arterioles, enlargement of the left ventricle on radiological examination. and left ventricular preponderance in the electrocardiogram. They were regarded as true examples of systemic hypertension, and as many as 23 exhibited polythelia, an incidence of 35 per cent.

In the second group of 42 subjects, the blood pressure was raised to the same high levels, but the retinal arterioles were natural, there was no radiological evidence of enlargement of the left ventricle, and the electrocardiogram was a physiological tracing. They were regarded as examples of the innocent state of systemic hypertonia (Evans, 1957), and only 2 showed polythelia, an incidence of 5 per cent.

Raised Pulmonary Blood Pressure. The pulmonary arterial pressure was expected to be somewhat raised in 302 patients, from atrial septal defect in 42, from ventricular septal defect in 13, from patent ductus arteriosus in 13, from mitral stenosis in 186, and from emphysema in 48 . They were separated into two groups, depending on the presence or absence of a degree of raised pulmonary arterial pressure that had caused significant enlargement of the right ventricle sufficient to produce right ventricular preponderance in the electrocardiogram.

In the first group of 73 patients, in whom the electrocardiogram showed right heart preponderance, and who were, therefore, instances of pulmonary hypertension, polythelia was present in as many as 32 , an incidence of 44 per cent.

In the second group of 229 patients, in whom the pulmonary arterial pressure was likely to be raised somewhat because of the nature of the associated lesion, but where the electrocardiogram showed no right ventricular preponderance, the cases were regarded as instances of pulmonary hypertonia. Polythelia was only present in 15 of them, an incidence of 7 per cent (Table III).

The incidence for the separate clinical states with which the raised pulmonary blood pressure was associated is shown in Table IV.

TABLE IV

Incidence of Polythelia in the Separate Clinical States in the Presence and in the Absence of PULMONARY HYPERTENSION

\begin{tabular}{|c|c|c|c|c|c|c|}
\hline \multirow{2}{*}{ Clinical state } & \multicolumn{3}{|c|}{ Pulmonary hypertension } & \multicolumn{3}{|c|}{ Pulmonary hypertonia } \\
\hline & Total & Polythelia & $\begin{array}{c}\text { Near } \\
\text { percentage }\end{array}$ & Total & Polythelia & $\begin{array}{c}\text { Near } \\
\text { percentage }\end{array}$ \\
\hline 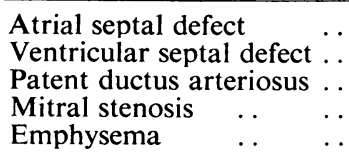 & $\begin{array}{r}17 \\
4 \\
1 \\
44 \\
3\end{array}$ & $\begin{array}{r}8 \\
1 \\
1 \\
18 \\
2\end{array}$ & $\frac{47}{-}$ & $\begin{array}{r}25 \\
9 \\
11 \\
142 \\
45\end{array}$ & $\begin{array}{l}1 \\
1 \\
0 \\
8 \\
6\end{array}$ & $\begin{array}{r}\frac{4}{-} \\
-6 \\
13\end{array}$ \\
\hline
\end{tabular}




\section{Discussion}

When an anomaly is present at birth as a lone lesion, it can be open to doubt whether it is developmental and genetic in its inception, or acquired by the fœtus in utero. Should the anomaly be associated with other developmental abnormalities, the supposition that it is congenital in nature will gain credence. For instance, multiple lesions in the heart at birth make it likely that any one of them is congenital, while among the associated extra-cardiac malformations that purport such a congenital hasis are cleft palate, hare lip, spider fingers, and supernumerary digits. Recently, a genetic relationship between peculiarly formed ears and renal agenesis or absence of one kidney, has been described (Hilson, 1957). In that polythelia is an atavistic manifestation, its high incidence in a disease, similarly suggests for it a genetic basis. Accessory nipples have been reported in more than one member of a family. Thus, Klinkerfuss (1924) recorded a hereditary incidence of polythelia through four generations, and Birkenfeld (1932) observed the condition in twins, while Graham-Campbell (1936) reported the case of a mother with ten accessory nipples and her baby with one such nipple.

The present investigation revealed a higher incidence of polythelia in congenital heart disease and in mitral stenosis than in healthy subjects, but in both clinical states this depended on the addition of pulmonary hypertension.

Thus, a significant finding was the high incidence of polythelia in patients in whom a congenital shunt as in atrial septal defect, ventricular septal defect, or patent ductus arteriosus, mitral stenosis, or emphysema, was associated with pulmonary hypertension; the incidence was 44 per cent compared with 7 per cent when these conditions were uncomplicated by pulmonary hypertension.

Moreover, in systemic hypertension the same high incidence of polythelia was apparent. Thus, it was 35 per cent in patients in whom a high systemic blood pressure was accompanied by left ventricular enlargement compared with only 5 per cent in healthy subjects manifesting hypertonia only.

Polythelia was also a common feature in patients exhibiting cardiomyopathy arising from a cause other than coronary arterial disease, for it was present in 14 out of 32 cases, an incidence of 44 per cent.

Thus, in both systemic and pulmonary hypertension and in cardiomyopathy, the incidence of polythelia was significantly high (Table V).

TABLE V

Showing the Incidence of Polythelia in Selected Cardio-Arterial Disease Compared with that in NORMAL SUbJECTS

\begin{tabular}{|c|c|c|c|c|c|}
\hline Clinical state & & Healthy & $\begin{array}{c}\text { Systemic } \\
\text { hypertension }\end{array}$ & $\begin{array}{l}\text { Pulmonary } \\
\text { hypertension }\end{array}$ & Cardiomyopathy \\
\hline $\begin{array}{lll}\text { Total . } & \ldots & \ldots \\
\text { Polythelia } & \ldots & \ldots \\
\text { Near percentage } & \ldots\end{array}$ & $\begin{array}{l}. . \\
\cdots \\
.\end{array}$ & $\begin{array}{r}1059 \\
49 \\
5\end{array}$ & $\begin{array}{l}66 \\
23 \\
35\end{array}$ & $\begin{array}{l}73 \\
32 \\
44\end{array}$ & $\begin{array}{l}32 \\
14 \\
44\end{array}$ \\
\hline
\end{tabular}

\section{SUMMARY AND CONCLUSIONS}

Polythelia, or the presence of accessory nipples, was sought in 2000 consecutive patients attending for examination of the heart. Some form of cardio-arterial disorder was discovered in 941 of them, while the remaining 1059 cases showed neither disease of the heart nor of any other system.

The incidence of polythelia among the healthy group proved to be 5 per cent.

Among those with cardio-arterial disease, polythelia was common in three clinical states. Thus, it was present in 35 per cent of patients with systemic hypertension showing contracted arteries, left ventricular enlargement, and left ventricular preponderance in the electrocardiogram, but in only 
5 per cent of subjects with systemic hypertonia, where the blood pressure was raised to impressive levels but where cardio-arterial derangement, including left ventricular preponderance in the electrocardiogram, was absent.

Next, the incidence of polythelia was 44 per cent in congenital cardiac shunts, mitral stenosis, or emphysema, when pulmonary hypertension was present, producing right ventricular hypertrophy and right ventricular preponderance in the electrocardiogram. In these same clinical states when the pulmonary arterial pressure might be raised, but where no right ventricular preponderance appeared in the electrocardiogram, representing a state of pulmonary hypertonia, the incidence of polythelia was only 7 per cent.

Polythelia was also a common finding (44\%) among patients with cardiomyopathy arising from a myocardial affection other than coronary arterial disease, and assuming the form of either myocarditis or a tardy fibrosis.

Since polythelia is a manifestation of atavism, its association with any particular disease suggests for it a genetic or congenital basis. Its high incidence in systemic hypertension, pulmonary hypertension and cardiomyopathy suggests for these three clinical states a congenital predisposition.

\section{REFERENCES}

Birkenfeld, W. (1932). Arch. klin. Chir., 168, 568.

Bruce, J. M. (1879). J. Anat. Phys. (Lond.), 13, 425.

Darwin, C. R. (1888). Descent of Man. London.

de Cholnoky, T. (1939). Arch. Surg. Chicago, 39, 926.

Evans, W. (1957). Lancet, 2, 53.

Graham-Campbell, R. (1936). Brit. med. J., 1, 471.

Guest, E. M. (1923). Brit. med. J., 2, 85.

Hamblen, E. C. (1945). Endocrinology of Woman. Illinois.

Hilson, D. (1957). Brit. med. J., 2, 785.

Keith, A. (1948). Human Embryology and Morphology. 6th ed. London.

Klinkerfuss, G. H. (1924). J. Amer. med. Assoc., 82, 1247.

Lichtenstern, O. (1878). Virch. Arch. Path. Anat., 73, 222. 